\title{
Albanon
}

Revistë kulturore

\section{Kolegjet arsimore arbëreshe}

\section{Denisa Tare}

Fillimi i shekullit XX, shënon një rritje të veprimtarisë kombëtare të italoshqiptarëve. Në këto lëvizje dhanë kontributin e tyre kolonitë arbëreshe në rajone të ndryshme si në Siçili, Napoli, Kalabri etj. ${ }^{1}$ Mjaft njerëz të kulturuar, studiues dhe lëvrues të gjuhës shqipe, të cilët me veprat e tyre letrare i kanë dhënë popullit arbëresh ushqim mendor dhe shpirtëror. Midis shkrimtarëve shqiptarë, nuk kanë munguar dhe përpjekjet për të hapur shkolla në arsimin shqip, me qëlllim që të ruajnë gjuhën, zakonet, doket e të parëve. ${ }^{2}$ Lëvizja kombëtare letraro-kulturore dhe arsimore e arbëreshëve, do të ndihmonte njëkohësisht në forcimin e kauzës kombëtare. Të shqetësuar për të ardhmen e vendit dhe pjesëmarrës aktivë në lëvizjet për autonomi dhe pavarësi të Shqipërisë, ishin shkrimtarët e shquar arbëreshë njëkohësisht dhe burra shteti si: Françesko Krispi (Francesco Crispi). Kontributi i atdhetarëve arbëreshë dhe lufta e tyre në mbrojte të çështjes shqiptare, u shpreh përmes veprimtarisë letrare, shtypit, protestave dhe memorandumeve. Arbëreshët e Italisë luajtën një rol të rëndësishëm në zhvillimin e arsimit, hapjen e shkollave shqipe dhe lëvrimin e gjuhës së tyre amtare. Zhvillimi arsimor është i lidhur gjithmonë me luftën e tyre për t’u afirmuar si etnitet kulturor dhe për t’i bërë ballë asimilimit nga kultura italiane që i rrethon. Arbëreshët e Italisë kanë tradita të mira në historinë e arsimit kombëtar, të shkollës shqipe, të mendimit pedagogjik shqiptar. ${ }^{3}$

Një vlerë të padiskutueshme në arsimimin e të rinjve arbëreshë, duke u kthyer në vatra kulturore, kanë dhënë hapja e dy kolegjeve arbëreshe, që u çelën në

1 Nikollë Loka, Kuvendi i Fanit dhe pamundësia e Piemontit Shqiptar, (Tiranë 2011), 4

2 A. Haxhi,T.Topalli, Kolegji i Shën Adrianit vatëre edukimit të dijeve, 9

3 Revista pedagogjike, nr. 3, 1977, 116. 
gjysmën e parë të shek. XVIII në Siçili dhe në Kalabri. ${ }^{4}$ Ato përbëjnë një pjesë të rëndësishme të kulturës së arbëreshëve të Italisë. Arbëreshët përmes hapjes së institucioneve arsimore të rëndësishme që u bënë më pas dhe vatra kulturore, i siguruan komuniteteve arbëreshe në Itali një zhvillim arsimor dhe kulturor. Njëkohësisht hapja e institucioneve arsimore si kolegji i Shën Adrianit në Kalabri, seminari arbëresh i Palermos 5 apo kolegji në Siçili, krijoi mundësinë e përgatitjes arsimore të shumë intelektualëve fetarë e laikë të kohës, por edhe dha kontribut me rëndësi të çmuar në luftërat për bashkimin e Italisë, Rilindjes e përgjithësisht kërkesave liridashëse dhe përparimtare të shoqërisë italiane brenda së cilës arbëreshët jetojnë. ${ }^{6}$

Letërkëmbimet e kohës mes atdhetarëve të ndryshëm, ndër të cilët dhe Dora d'Istria, vënë në dukje përjekjet e arbëreshëve të Kalabrisë dhe Siçilisë për rimëkëmbjen e Shqipërisë. Lëvizjet kulturore-arsimore, D'Istria i shikonte si pjesë përbërëse e lëvizjes kombëtare shqiptare. Në vitet 60 të shekullit XIX, ishin krijuar kushtet e një lëvizjeje të organizuar për mbarëvajtjen e arsimit dhe të diturisë. Kjo ishte kërkesë e domosdoshme e kohës për të forcuar dhe nxitur masat popullore shqiptare në nisjen e luftës së përbashkët për mbrojtjen e çlirimin e atdheut. Në këtë luftë nuk mungoi dhe nuk mund të mohohet kontributi i arbëreshëve ndaj vëllezërve të tyre të mëmëdheut përtej Adriatikut.

Nga fillimi i vitit 1867, intelektualë arbëreshë si Jeronim de Rada, Dhimitër Kamarda, Vinçens Dorsa, etj., morën iniciativën të parashtronin në parlamentin italian një kërkesë për futjen e gjuhës shqipe në programin e shkollave dhe institucioneve arsimore si dhe për gjallërimin e jetës në kolegjet arbëreshe. ${ }^{7}$ Dora d'Istria përmes letrave dëshmonte vlerën e atdhetarëve arbëreshë në rilindjen e popullit shqiptar dhe bënte çmos për kthimin e kolegjeve në vatra arsimore kombëtare shqiptare. Në një nga letrat e saj shkruante: "Shqiptarët e Italisë së Jugut, nga vetë pozita e tyre, nga patriotizmi i tyre i patundur, janë pikërisht ata që do të bëjnë të rilindë një popull që ka pasur fatkeqësira në shekuj me radhë".

Nevojën e zhvillimit të arsimit, Jeronim de Rada një tjetër atdhetar shqiptar e konkretizon me themelimin e shoqërive patriotike, me daljen e revistave dhe

4 Revista pedagogjike, nr. 2, 1974, 134

5 Loka, Kuvendi i Fanit dhe pamundëisia e Piemontit Shqiptar, 42

6 Revista Nëntori nr. 3, 1983, f. 187.

7 Ahmet Kondo, Dora d'Istria për çështjen kombëtare shqiptare, Tiranë: Naim Frashëri, 1967,29

8 Letër e Dora d'Istrias, Livorno, 15 tetor 1868 


\section{Albanon}

\section{Revistë kulturore}

gazetave dhe me botimin e veprave të ndryshme, gjë të cilën e konsideron zgjim nacional me shumë dobi për të ardhmen e tërë popullit shqiptar. ${ }^{9}$ Në vitin 1736, për herë të parë filloi të shkruhej gjuha shqipe ${ }^{10}$ dhe kësisoj për arbëreshët filloi një epokë e re e arsimit kombëtar dhe një epokë e re e gjuhës shqipe. Në gjysmën e dytë të shekulit XVIII, u ngritën dy institucione arsimore që përmbushën zbrazëtinë e jetës shpirtërore të arbëreshëve. Arbëreshët kërkonin $t ` i$ arsimonin bijtë e tyre me një kulturë të pasur që të mos mbeteshin prapa vendasve në arsim dhe qytetërim. Kultura arbëreshe ndjehej e kërcënuar nga fushata e kishës katolike të Italisë së Jugut kundër ritit bizantin që ndiqej nga komunitetet arbëreshe.

\section{Kolegji “Shën Adrianit”}

Një kthesë vendimtare në historinë fetare, politike, kulturore dhe civile të arbëreshëve të Italisë shënoi themelimi i dy qendrave arsimore për arbëreshët e Italisë, kolegji "Korsini” në Shën Benedikt (S. Benedeto Ullano) ose "Shën Adrianit" në Kalabri si dhe seminari arbëresh i Palermos në Siçili. Këto masa që mori Selia e Shenjtë, shërbyen për ruajtjen e traditës kishtare bizantine ndër arbëreshët e Italisë. Në fakt, këto dy shkolla, krahas ndihmës për ruajtjen e ritit bizantin në Itali, u bënë dhe qendrat kryesore të formimit kulturor për intelektualët arbëreshë deri në fund të shekullit XIX. Nevoja për t’u dalluar nga grekët, i shtyu klerikët intelektualë arbëreshë të vinin në pah veçoritë gjuhësore, fetare dhe kulturore të etnisë së tyre, duke i hapur rrugë çështjes kombëtare që do të lindte në dhjetëvjeçarët më vonë. Përveç formimit të intelektualëve dhe klerikëve progresistë, që luajtën një rol me rëndësi në Rilindjen italiane, këto dy institucione arsimore favorizuan që në fillim lindjen e vetëdijes kombëtare mes arbëreshëve duke zhvilluar një traditë intelektuale. ${ }^{11}$ Kështu kërkesat dhe dëshirat e tyre për t'u integruar në jetën e vendit nisën më së pari në vitin 1577, kur papa Gregori XIII, mori nismën për hapjen në Romë të një kolegji, i cili kishte për qëllim të përgatiste klerikë të ushtronin meshtarinë në ritin greko-katolik në vise të ndryshme të Italisë. Këtu përfituan edhe disa nxënës arbëreshë si: Stefano Rodota, bir i një familjeje të përmendur bujare nga Shën Benedikt Ullano-

9 Muhamed Hysaj, Veprimtaria publicistike e De Radës në revistën Flamuri i Arbrit, Jehona, Shkup, nr. 6, 1968, f. 38

10 Po aty

11 Françesco Altimari, Urat e Arbrit, 25 
ja. ${ }^{12}$ Pasi përfundoi studimet dhe nisi ushtrimin e detyrës, ai filloi të mendonte për themelimin edhe në Kalabri të një kolegji të tillë, i cili do të mund të formonte priftërinjtë e ardhshëm edhe në kolonitë italo-shqiptare, por njëkohësisht të shërbente edhe për arsimimin e popullatës së kësaj zone. Për këtë qëllim iu drejtua me një lutje papa Klementit XI, kërkesë e cila u pranua nga kryetari i kishës katolike dhe u caktua për këtë funksion ndërtesa e Badisë në katundin arbëresh Shën Benedikt Ullano. Por Papa ndërroi jetë dhe qëllimi tij u realizua vetëm kur në krye të kishës katolike u vendos papa Klementi XII. Kjo kërkesë gjeti mbështetjen e Papës dhe me vendim të veçantë, më 5 tetor 1732, u shpall krijimi i kolegjit italo-grek "Korsini" ${ }^{13}$ dhe drejtor i tij u vendos Feliçe Samuel Rodota, nga familja Korsini e Firences. Kolegji mori emrin "Korsini” në nder të tij dhe familjes së tij. Ai siguroi prej thesarit papal shumën prej 12.000 skudesh $^{14}$ të arta, me të cilat ngriti kolegjin.

Ferdinandi IV, me dekret të datës 1 mars 1794, vendos që kolegji i Ullanos të trasferohej në Manastirin e "Shën Adrianit" si dhe akreditoi pasuri të tjera veç atyre që kishin në Ullano. ${ }^{15}$ Emri i kolegjit u ndryshua nga Shën Ullano Korsini në kolegji Shën Adriani. Qëllimi i krijimit të kolegjit ishte të përgatiste të rinj të arsimuar dhe të kulturuar, po ashtu programe arsimore për t’u siguruar njohuri të rinjve në drejtime të ndryshme si për gjuhën greke, në disiplina të lira, në shkenca, në teologji dhe në ritet fetare. ${ }^{16} \mathrm{Në}$ këtë mënyrë do të përgatiteshin klerikë të rinj italo-shqiptarë me baza të thella katolike. Siç shprehej De Rada, ky kolegj u çel "si një derë e madhe drite të re e të butë, për të gjitha shtëpitë arbëreshe, nga të cilat, ata që patën mundësi, menjëherë dërguan bijt e tyre për të mësuar e për t’u arsimuar". ${ }^{17}$

Kolegji i Shën-Adrianit mori shumë shpejt emër, u njoh si vatër kulturore dhe arsimore duke përgatituar një gjeneratë të tërë studentësh elitarë, përgatiti dijetarë e shkrimtarë të njohur, që i lanë nder e lavdi gjuhës amtare e letërsisë shqiptare. Ai qe vendi ku u bashkua dhe u fuqizua kultura arbëreshe e personalitete shqiptare që kanë punuar eluftuar për t’i ruajtur të pastra traditat kombëtare, ngaqë u kthye në një vatër të kulturës shqiptare dhe arbëreshe, si

12 Artan Haxhi,Tefë Topalli, Kolegji i Shën Adrianit vatër e edukimit të dijeve, 9

13 Don Salvatore Scura, II colegio italo-albanese Corsini in Calabria, II Bolletino, .72

14 Vincenso Dorsa, Shqiptarët hulumtime dhe mendime, Botimet Enciklopedike, Tiranë, 2010

15 Il colegio San Adriano Coriliano, Flamuri i Arbrit, Calabro, viti I, nr. 30 prill 1884, 16-161

16 L'emigrazione in Italia. II colegio italo-albanese, Popoli, Viti 1, Nr.10, shtator 1941.

17 Kabashi, Jeronim De Rada poetika e poemave, 92 


\section{Albanon}

\section{Revistë kulturore}

dhe luajti rol në pasurimin e kulturës përparimtare italiane. Pionierët e parë që ndihmuan në çeljen e tij qenë Stefan Rodotá dhe Samuel Rodotá nga familja e shquar e Koronjeve të Shën Benediktit. Për disa vjet, nga 1732 deri më 1740, kolegjin e drejtoi Samuel Rodotá. Ai u mundua të fuqizonte institutin, jo vetëm nga ana ekonomike, por dhe nga ana pedagogjike dhe arsimore. Ai vdiq në moshë të re dhe pas tij drejtimin e mori Kolë de Markis nga Ungra, pasuar më vonë nga Imzot Xhaçinto Arkiopoli (Giacinto Archiopoli) nga Shën Dhimitër Korona, i cili drejtoi me sukses këtë institucion për 18 vjet. ${ }^{18}$ Më 1792, në krye të kolegjit erdhi Françesko Buliari nga Shën Sofia, i cili drejtoi me zotësi dhe i dha emër kolegjit, jo vetëm ndër arbëreshët, por edhe në mbarë Kalabrinë. Ai siguroi ndihma të konsiderueshme nga ana e qeverisë së kohës, bashkë me pasurinë e themeluesve të Shën Adrianit dhe të ardhura të tjera që zotëronte kolegji në Shën Dhimitër Korona. Këtyre pasurive iu shtuan dhe ato që zotëronin: kolegji në Shën Benedeto, në Korolei, në Arki, Spexana Albaneze (Spezzana Albanese), etj. ${ }^{19}$ Më 1 mars 1794, kolegji u vendos në manastirin e Basilianëve të Shën Adrianit dhe mori emrin kolegji i Shën Adrianit. Gjatë këtyre viteve, kolegji pati arritje në të gjitha drejtimet duke e ngritur lart cilësinë e mësimëdhënies, të edukatës e disiplinës e duke pasuruar më tej biblotekën e tij. Por për fat jo të mirë, pati kohë turbullirash e trazirash në Itali dhe kolegji u bë objekt sulmi dhe shkatërrrimi, ndërsa drejtuesi i saj humbi jetën. Kjo shkaktoi mbylljen e tij për 8 vjet. Më 31 janar 1807, në krye të kolegjit vendoset Domenico Bellushi nga Frashineto. Ai e drejtoi kolegjin për çerek shekulli duke bërë që t'i rritej fama dhe autoriteti. Kolegji u kthye në një fidanishte dijesh ku përgatiteshin dhe edukoheshin të rinj, të cilët do të bëhen veprimtarë të shquar të Rilindjes italiane; shumë prej të cilëve do të ishin pjesëmarrës në revolucionin e viteve 1844, 1848, $1860 .^{20}$ Përmendim Jeronim de Rada, Vincenso Dorsa, Domenico Damis, Domenico Mauro, etj. Deri në vitin 1842, kolegjin e drejtoi Gabriele de Markis nga Ungra, pastaj erdhi Anton Markianoi nga Maqi, mirëpo për shkak të mendimeve të tij liridashëse $\mathrm{u}$ hoq nga drejtues dhe më pas edhe $\mathrm{u}$ burgos. Të njëjtin fat pati edhe pasuesi i tij, Vinçenc Rodotá. Më 1854, mbreti Ferdinandi II jep urdhër që kolegji të mbyllej me akuzën se po përgatiste djelmëni kryengritëse. ${ }^{21}$ Kolegji nuk funksionoi më, deri kur drejtimin e tij e mori peshkopi A. Franko nga Mezojuso (Siçili), i cili nuk shkëlqeu fort

18 A.Haxhi,T.Topalli, Kolegji i Shën Adrianit vatëre edukimit të dijeve, 11

19 Mandalari, Indipendenca Shqiptare, Tiranë: Uegen, 2008

20 Po aty

21 A.Haxhi, T. Topalli, Kolegji i Shën Adrianit vatër e edukimit të dijeve, 12 
dhe për pasojë kolegji nuk pati asnjë përparim. Për këtë arsye u zëvëndësua nga peshkopi i fshatit italian Rosano, i cili e mbajti deri më 1860, kur në Kalabri hynë forcat e Garibaldit. Më 20 tetor 1860, Garibaldi shkruante nga Kazerta për kontributin e dhënë në ekspeditën e Të Njëmijëve, ku deklaroi botërisht: "Arbëreshët janë heronj, të cilët kanë dalluar në të gjitha luftrat kundër tiranisè!"22 Dhe në shenjë mirënjohjeje, Garibaldi, më 20 tetor 1860 lëshoi dekretin historik: "Duke marrë parasysh kontributin e shënuar që trimat dhe zemërbujarët arbëreshë $i$ kanë dhënë çështjes kombëtare, deklarojmë: 'Sa të mbarojnë nevojat e kësaj lufte dhe të bëhet bashkimi i Italisë. Thesari i Napolit detyrohet të derdhë menjëherë 12 mijë dukatë për zmadhimin e kolegjit të San Adrianos. ${ }^{\text {"3 } 3}$ Më pas, nga Napoli në 26 tetor, duke marrë në konsideratë kushtet aktuale të kolegjit italo-shqiptar Shën Adriano në Kalabri, vendos në emër të mbretit Viktor Emanueli II, nënshkrimin e dekretit të mëposhtëm:

1. Tërhoqi vendimin e qeverisë burbone që e vinte kolegjin e Shën Adrianit nën varësinë e arqipeshkvit Rossano.

2. Caktoi një komision për ta drejtuar atë. Në komision bënin pjesë Antonio Markianoi nga Maqi (kryetar), Benedeto Skura nga Vakarico dhe Saverio Elmo nga Firmoza.

3. Komisioni do të marrë masa për të krijuar katedra të tjera krahas atyre ekzistente të gjuhës franceze, italiane, katedra të fizikës, të drejtësisë etj. ${ }^{24}$

Komisioni me punën e zellin e tyre e zbukuruan dhe e lulëzuan kolegjin si në kohët e para. Për një periudhë të gjatë kohe, gati 25 vjet, kolegji i Shën Adrianit u drejtua nga Antonio Markiano (Antonio Marchiano) i cili i dha një zhvillim të madh dhe një emër akoma më të mirë atij. Ky kolegj ishte shndërruar tashmë në një qendër kulturore dhe arsimore, prej së cilës dolën djem të rinj dhe të përgatitur. Kështu ndodhi edhe kur në krye të saj do të vendosej Imzot Zef Skiroi. Nën drejtimin e tij dhe falë insistimit të Jeronim de Radës, u arrit të themelohej katedra e gjuhës shqipe. Krijimi i katedrës së gjuhës shqipe në kolegjin arbëresh të Shën Adrianit ndihmoi për mësimin dhe përhapjen e gjuhës shqipe me shkrim nëpër ngulimet arbëreshe të Italisë. Shqipja deri atëherë përdorej nga nxënësit vetëm në kumtimet me gojë me njëri-tjetrin. Në vitin 1849, me ndërhyrjet dhe përpjekjet e Jeronim de Radës, u lejua të futej në Kolegjin e Shën Adrianit mësimi i gjuhës shqipe

22 Mandalari, Indipendenca shqiptare, 50

23 "Il Colegio albanese", Flamuri i Arbrit,Viti 1, nr.5, 30 shkurt 1884,.93.

24 Po aty, f.94 


\section{Albanon}

\section{Revistë kulturore}

dhe De Rada, u bë mësuesi i parë i shkollës shqipe. Dëshira e tij për hapjen e shkollës në gjuhën shqipe, vihet re dhe në letërkëmbimet e kohës. Një fakt të tillë e pohon dhe letra dërguar atij nga Domeniko Damis. Çezare Kantu në veprën Rite, gjuha shqiptare mes kundërtive të mëdha, theksonte: "Jeronim de Rada, themeloi një gazetë, kompozoi një poemë dhe është konsideruar si patriarku $i$ gjuhës. Duke $i$ shkrirë gjithë të ardhurat dhe jetën për ngritjen e vendit dhe gjuhës së tij, më në fund ia doli mbanë të ngrinte një katedër shqiptare në kolegjin e Shën Dhimitër Koronës. Këtë katedër e mbajti fillimisht De Rada, i cili në 1892, e mori nga një admirues i tij, Paskuale Ulano, asakohe ministër i Parlamentit italian dhe që e kishte njohur përmes Francesco Krispit." Në këtë katedër, në Aioli, gazetë e Frederiko Miskul shkruhet: “...me qëllim që të mbahet i gjallë kulti i gjuhës kombëtare të kolonive shqiptare, në kolegjin Shën Dhimitër do të krijohet katedra për studimin dhe mësimin e kësaj gjuhe... nga profesori Jeronim de Rada". ${ }^{25}$ Lidhur me formimin e tij dhe kërkesave për ndihmë nga shqiptarët, shihet në letrat dërguar në kolegjin e Shën Adrianit, siç del edhe nga një interpelancë mbi politikën e jashtme italiane në Shqipëri prezantuar në parlament nga Luixhi Gaetani di Laurencana. ${ }^{26} \mathrm{Në} \mathrm{një} \mathrm{letër}$ të dërguar nga Françesko Mauro një personi të panjohur, thuhej se duhej që të mblidheshin fonde dhe t’i bëhej thirrje rinisë që të ishte gati për një ndërhyrje në ndihmë të Shqipërisë. Më 15 nëntor 1902, vetëm tre muaj para se të vdiste, në fjalën përuruese të vitit shkollor, De Rada theksonte: "Rihapja e një shkolle shqipe në Kolegjin tonë na mbush, o djelmosha bashkatdhetarë, me një kënaqësi e me besim në të ardhmen. Prandaj, ngritjen e katedrës së re të gjuhës shqipe, mund ta konsiderojmë, në radhë të parë, si faktor historik, me anë të së cilës do të përkrahim ringjalljen e popullit shqiptar." ${ }^{27}$ Gjatë periudhës që zgjati mësimi i shqipes në kolegjin e Shën Adrianit, u botuan një varg tekstesh shkollore, programesh e planesh mësimore, që janë me shumë rëndësi për historinë e mendimit pedagogjik shqiptar dhe të shkollës shqipe. Mund të përmendim "Leksione të gjuhës shqipe" (1892), "Konferenca mbi vjetërsinë e gjuhës shqipe” (1893), "Tiparet e gjuhës shqipe dhe gramatika e saj” (1894), "Abetarja e gjuhës shqipe" (1896), etj. ${ }^{28}$ Kolegji i Shën Adrianit, pikërisht në kohë të vështira e të turbullta për Shqipërinë, shërbeu edhe si qendër kulture e edukimi për rininë shqiptare. Që prej vitit 1898, deri më

25 Mandalari, Indipendenca shqiptare., 52.

26 AQSH, F.24,D.8, f. 1-23

27 Jup Kastrati, Jeronim de Rada (Jeta dhe vepra). Tiranë: Shtëpia Botuese "8 Nëntori", $1979,1979,140$

28 Kabashi, Jeronim de Rada poetika e poemave, 93 
1919, aty ndoqën mësimet mbi njëqind intelektualë shqiptarë, të cilët u bënë veprimtarë entuziastë në shërbim të atdheut e të arsimit kombëtar. Lidhjet me Italinë nuk i kishin ruajtur vetëm shkrimtarët arbëreshë, por njëkohësisht dhe klerikët katolikë shkodranë, mirditorë dhe malsorë, të cilët përgjatë shekujve kishin përfunduar studimet në Itali. Në vitin 1904, në kolegjin e Shën Adrianit në Shën Dhimitër Korona, vazhdonin studimet Kol Kamsi, Pjetër Troshani, Luigj Kodheli, Zef Kurti, Lazër Prendushi, Ndoc Martin Camaj ${ }^{29}$ dhe Preng Doçi që kishte përfunduar studimet në Kolegjin Urban në Romë në vitin 1871. Në vitet e fundit para pavarësisë, De Rada bashkëpunon me patriotë shqiptarë në të mirë të çështjes kombëtare, si Luigj Gurakuqi, i cili dhe ai kishte përfunduar studimet e mesme në Shën Dhimitër Korona dhe studimet e larta në Napoli. Kolegji i Shën Adrianit, ishte një seminar për përgatitjen e klerikëve arbëreshë të ritit grekbizantin. Megjithatë, intelektualët arbëreshë nuk e humbën identitetin e tyre kombëtar edhe në fillimet e këtij institucioni në shekullin XVIII, kur popujt identifikoheshin jo sipas gjuhës apo kulturës, por sipas ritit fetar që aplikonin. Shekulli i ri përkon tashmë me rritjen e vetëdijes kombëtare këtej dhe përtej detit. Kjo do të shënojë një kthesë të dukshme të ecurisë së këtij institucioni, sidomos në vitin 1900, kur në krye të kolegjit vendoset Anxhelo Skalabrini (Angelo Scalabrini), i cili u kujdes që ai të zgjerohej edhe me hapjen e një shkolle normale në 1905, ku pati nxënës vetëm nga Shqipëria. Skalabrini synonte ta kthente kolegjin në lulëzimin e dikurshëm, por dhe ta përforconte atë dhe ta kthente në një Institut Ndërkombëtar ${ }^{30} q e ̈$ mund të ishte plotësues i shkollave italiane në Orient. Qeveria italiane akordoi bursa të veçanta vetëm për nxënës nga Shqipëria të cilët do të formonin mësues të ardhshëm. Kështu kolegji mori karakter mbarëkombëtar, duke u shndërruar në një qendër kulturore të edukimit të djemve të rinj shqiptarë, kohë në të cilën vendi ndodhej nën pushtimin osman. ${ }^{31}$

Kolegji i Shën Adrianit, sikurse ka vënë në dukje Antonio Guarashi (Guarasci), gjatë shekullit XIX ka qenë qendra kulturore më aktive e jugut në mbështetje të Rilindjes kombëtare italiane. Gjatë viteve 20-30 të shekullit XIX, në këtë kolegj, gjejmë një sërë figurash të rëndësishme të kulturës arbëreshe, si Jeronim de Rada, Domenico Mauro, Domenico Strigari, Luigi Petrasi dhe Angelo Bazile. Gjatë gjysmës së parë të atij shekulli, kolegji kthehet në qendrën më aktive të lëvizjes antiburbone, jo vetëm në nivel lokal, por dhe

29 Loka, Kuvendi i Fanit dhe pamundësia e Piemontit Shqiptar, 42

30 "Colegio di San Adriano," La Nazione Albaneze, Nr.14, 31 korrik 1900, 7

31 A. Haxhi, T. Topalli, Kolegji i Shën Adrianit vatëre edukimit të dijeve, 14 


\section{Albanon}

\section{Revistë kulturore}

rajonal duke u bërë i vetmi institucion që mbështeti organisht Rilindjen në jug të Italisë. Krahas intelektualëve të përmendur në fund të shekullit XIX, nuk munguan edhe intelektualë të tjerë arbëreshë që vijuan të mbajnë gjallë angazhimin politik dhe kulturor, në mbështetje të çështjes kombëtare dhe të identitetit arbëresh. Një rol të rëndësishëm në forcimin e ndërgjegjës kombëtare, padyshim luajti dhe kolegji i Shën Adrianit, i cili u forcua së tepërmi me hapjen e katedrës së gjuhës dhe letërsisë shqipe. Kolegji arbëresh zë një vend të merituar në historinë e arsimit tonë kombëtar. Ai mbajti të gjallë gjuhën dhe kultivoi dashurinë për atdheun e të parëve, Shqipërinë dhe përgatiti siç përmendëm dhe më lart, breza të tërë të inteligjencës kombëtare arbëreshe: dijetarë, gjuhëtarë, arsimtarë, etnografë, historianë, shkrimtarë, folkloristë dhe studiues të shquar, të cilët i kanë sjellë kontribute të vyera kulturës kombëtare shqiptare, çështjes shqiptare në periudha të caktuara historike. Duke punuar në kolegj, De Rada bashkëpunoi me rilindas të shquar shqiptarë, si Zef Jubani e Thimi Mitko, Luigj Gurakuqi, i cili ishte nxënës i De Radës, pa harruar bashkëpunimin me Aleksandër Xhuvanin, studiuesin e çmuar të gjuhës shqipe. A. Xhuvani përmendet dhe si mësues i gjuhës shqipe në Shën Dhimitër Korona. Mund të përmendim, ndër të tjerë, nxënësit e De Radës, poetët e njohur arbëreshë Zef Serembe e Bernard Bilota. Një numër i mirë dijetarësh arbëreshë ishin marrë me studimin e gjuhës shqipe, me folklorin, etnografinë dhe historinë e popullit shqiptar. Përmendim dy shkrimtarë dhe studiues të mëdhenj shkodranë, si Arshi Pipa dhe Martin Camaj, jo vetëm kontributin shqiptar, por dhe kontributin arbëresh për kulturën evropiane gjatë mesjetës e më tej. "Falë kësaj qendre dhe të tjerave si ajo, - thekson Camaj, - nga përfaqësuesit e diasporës shqiptare në Itali, që përdorën italishten si gjuhë shkrimi, tue përkthy në këtë gjuhë disa prej vargjeve poetike, Shqipëria dhe populli shqiptar, deri atëherë thuajse të panjohur dolën në skenën evropiane. Ndërmjet tyre, kultura shqipe lidhet me kulturën perëndimore, tue u ba pjesë e saja." ${ }^{2}$ Martin Camaj njëkohësisht ka bërë studime për hapësirën shqiptarofolëse të diasporës arbëreshe duke nënvizuar dhe rëndësinë e qendrave arsimore në jug të Italisë. Vite më parë ai shprehet: "Ata që mërguan n'Italinë e Jugut, shumica e tyre ortodoksë, disa prej të cilëve erdhën nga Greqia, ruajtën gjuhën shqipe dhe mbajtën fenë e tyre ortodokse." Arbëreshët në vitet 30 të shekullit XIX, qenë të zotët të themelojnë qendrat e veta arsimore: kolegjin Korsini (më vonë Shën Adriani) dhe seminarin italo-grek të Palermos. Prej këtyre qendrave kulturore dolën dijetarët e letrarët arbëreshë të cilët, nën ndikimin, në fillim të iluminizmit 
dhe më vonë të romantizmit, prodhuan veprat e para mbi gjuhën shqipe dhe popullin shqiptar. ${ }^{33}$ Lidhjet mes dijetarëve dhe intelektualëve të Shkodrës me botën arbëreshe e vë në dukje përkthyesi Lazër Shantonja, kur shkruan: "një kontribut të madh e të fuqishëm $i$ kanë dhënë zgjimit kombëtar e intelektual të vendit tonë edhe shkollat italiane ashtu si në Itali dhe në Shqipëri. '34

Gjatë shekujve XIX-XX, intelektualët arbëreshe u vunë në pararojë të zhvillimeve kulturore, politike, civile dhe demokratike, jo vetëm në komunitetet e tyre, por për gjithë Italinë e Jugut. Mjaft intelektualë dhe shkrimtarë arbëreshë vijuan të mbajnë gjallë angazhimin politik dhe kulturor, në mbështetje të çështjes shqiptare dhe në mbrojtje të identitetit arbëresh. Mes tyre përmendim Agustino Ribeko (Ribecco), Antonio Skura (Scura), Kozmo Serembe, Orazio Kapareli (Capparelli), Terenc Toçi (Tocci) dhe Salvatore Braile. U shqua pa dyshim dhe Anselmo Lorekio (Lorecchio) si trashëgimtar politik i De Radës. Për kontributin e dhënë përmendim dhe një grup tjetër intelektualësh dhe shkrimtarësh arbëreshë si vetë Zef Serembe, por dhe Domeniko Antonio Markeze (Domenico Antonio Marchese) dhe Aristide Manes që e mbyllën jetën në mërgim. Përfshirja në katedrën e gjuhës shqipe në organikën e liceut të Shën Dhimitër Koronës,vetëm teorikisht mund të duket si një lloj njohjeje zyrtare nga ana e administratës shtetërore italiane të Pakicës arbëreshe.

Mund të themi se dy nisma të rëndësishme që tregojnë ndikimin e politikës italiane ndaj arbëreshëve, janë hapja e katedrës së gjuhës dhe letërsisë shqipe në vitin 1900 pranë Institutit Oriental të Napolit si dhe përfshirja e lëndës gjuhë dhe letërsi shqipe në kolegj. Në shekullin XIX, pati një rritje të ndërgjegjes politike tek intelelektualët arbëreshë, si dhe rritje të pjesëmarrjes së tyre në luftën kundër absolutizmit dhe afirmimit të ideve demokratike dhe lirive kombëtare. Pikërisht kjo bëri që të ndërgjegjësohen qarqet politike dhe kulturore evropiane mbi çështjen kombëtare. ${ }^{35}$ Gjatë dhjetëvjeçarit të fundit të shekullit XIX, qeveria e drejtuar nga Françesko Krispi, përcaktoi shndërrimin e kolegjit në institut mbarëkombëtar arbëresh, ku krahas studentëve dhe profesorëve arbëreshë do të përfshiheshin dhe studentë dhe profesorë të rinj nga Shqipëria (asokohe nën pushtimin osman). Në mes këtyre intelektualëve të rinj shqiptarë që më vonë luajtën një rol të rëndësishëm në politikën, kulturën dhe shkencën shqiptare, përmendim

33 Po aty

34 Lazër Shantonja, Botime Françescane, Shkodër, 2005, 490.

35 Altimari, Kolegji i Shën Adrianit vatëre edukimit të dijeve, 34 


\section{Albanon}

\section{Revistë kulturore}

Luigj Gurakuqin, Gaspër Jakov Mërturin, Aleksandër Xhuvanin, Ndoc Martin Camajn, Kolë Kamzin, Mehdi Frashërin, Avni Rustemin, etj. Gjatë regjimit fashist, ndonëse në masë më të vogël, kolegji i Shën Adrianit vijoi të luante një rol të rëndësishëm në formimin e elitës së re shqiptare të gjysmës së dytë të shekullit XX. Përmendim këtu personalitete të rëndësishme si: gjuhëtari Kostaq Cipo apo Spiro Koleca. Fluksi i nxënësve shqiptarë në kolegjin arbëresh vijoi deri në rënien e regjimit fashist. Gjuha shqipe nuk u hoq nga programet mësimore të liceut shtetëror të Shën Dhimitrit, krahas hapjes së katedrave universitare të gjuhës dhe letërsisë shqipe në Palermo (1932) dhe në Romë (1939). ${ }^{36} \mathrm{Një} \mathrm{kthesë} \mathrm{të} \mathrm{vërtetë} \mathrm{në} \mathrm{historinë}$ fetare, politike, kulturore, qytetare të komunitetit arbëresh në Itali, shënoi themelimi i dy kolegjeve arbëreshe në Kalabri dhe Siçili. Këto qendra ishin kolegji Korsini dhe Seminari i Palermos në Siçili. Këto dy seminare, përveç kontributit vendimtar që patën për ruajtjen e ritit fetar në traditën greke në Itali, përfaqësuan dhe qendrat kryesore të formimit dhe përgatitjes teologjike dhe kulturore të një pjese të mirë të klerit dhe inteligjencës arbëreshe në fund të shekullit XIX.

\section{Bibliografia}

1. "Colegio di San Adriano," La Nazione Albaneze, Nr14, 31 korrik $1900, .7$

2. Ahmet Kondo, 'Dora D"Istria për çështjen kombëtare shqiptare" Tiranë: Naim Frashëri, 1967, 29

3. Altimari, Françesco Urat e Arbrit ( Shtëpia botuese:

Naimi,Tiranë,2015), .25

4. AQSH,f.24,D.54/1,f.13

5. AQSH,F.24,D.54/4,f.210-211

6. ASHQ,F.24 D54/11

7. ASHQ,F.24,D.53,f. 21

8. Dorsa,Vincenso Shqiptarët hulumtime dhe mendime, (Botimet Enciklopedike, Tiranë, 2010

9. Gazeta "La Nazione Albaneze" , Nr 10, Pellagario - Katanzaro, 1913, 7

36 Po aty 
10. Gazeta "La Nazione Albaneze", Nr 3, 7

11. Girolomo De Rada”, Djalëria,viti IX,V.II,Nr.4, 1928,.7

12. Hajredini Xhemi, .Diaspora Historike dhe kongresi i pare I shqiptarëve të Italise

13. Hysa ,Muhamed ., Veprimtaria publicistike e De Radës në revistën "Flamuri i Arbrit", Jehona, Shkup,nr.6,1968,f.38

14. Il Colegio albanese", Flamuri i Arbrit, , Viti 1, nr.5, 30 shkurt $1884, .93$

15. Kastrati, Jup. Jeronim de Rada (Jeta dhe vepra). Tiranë: Shtëpia Botuese "8 Nëntori”, 1979

16. Lazër Shantonja, (Botime Françescane, Shkodër, 2005),

17. Letër e Dora D’Istrias, Livorno, 15 tetor 1868

18. Loka,Nikolle. Kuvendi i Fanit dhe pamundeisia e Piemontit Shqiptar,Tiranë 2011

19. Mandalari, Oreste Camillo. Indipendenca shqiptare Tiranë: Uegen, 2008

20. Mehmeti , Drita . "Studime historike".Nr. 4 ,Tiranë (1980): 143.

21. Revista "Nëntori” nr. 3, 1983, f. 187.

22. Revista pedagogjike", nr. 2, 1974, 134

23. Revista pedagogjike”, nr. 3, 1977, 116.

24. Scura, Don Salvatore, "Il colegio italo-albanese Corsini in Calabria," Il Bolletino, .72

25. Skendi,Stavro. Zgjimi Kombëtar Shqiptar 1878 - 1912 .(Tirane: Phoenix..2000),.202 